Research Article

\title{
Flexural Behavior of Slab-Rib Integrated Bridge Decks with GFRP Skin and Polyurethane Foam Core
}

\author{
Jing Li, ${ }^{1}$ Jun Wang $\mathbb{C}^{1},{ }^{1}$ Bishnu Prasad Yadav, ${ }^{1}$ Jiye Chen, ${ }^{2}$ Qiang Jin, ${ }^{3}$ and Weiqing Liu $\mathbb{C D}^{1}$ \\ ${ }^{1}$ College of Civil Engineering, Nanjing Tech University, Nanjing, China \\ ${ }^{2}$ School of Civil Engineering and Surveying, University of Portsmouth, Portsmouth, UK \\ ${ }^{3}$ College of Civil and Hydraulic Engineering, Xinjiang Agricultural University, Urumqi, China
}

Correspondence should be addressed to Jun Wang; wangjun3312@njtech.edu.cn

Received 26 June 2019; Accepted 11 August 2020; Published 3 December 2020

Academic Editor: Ivan Giorgio

Copyright (C) 2020 Jing Li et al. This is an open access article distributed under the Creative Commons Attribution License, which permits unrestricted use, distribution, and reproduction in any medium, provided the original work is properly cited.

\begin{abstract}
This paper presents experimental and analytical studies on flexural behavior of slab-rib integrated Sandwich composite decks. The influences of layers of glass fiber-reinforced polymer (GFRP) facesheets, foam densities, and the existence of webs and cross beams are discussed herein. The test results showed that the existence of vertical webs remarkably improved the debonding of the facesheets from the foam core, thus increasing the ultimate load by $59 \%$ compared with the specimens without webs. However, the existence of horizontal webs has insignificant effect on the failure mode and ultimate load. Increasing the number of layers of GFRP facesheets from 2 to 4 and 6 results in 100\% and 214\% increments in ultimate loads, respectively, while the specimen with lower density of foam had a higher ultimate load than the specimen with higher density of foam due to deformation compatibility between GFRP skins and foam core with low density. The analysis software Abaqus Explicit was used to simulate the flexural behavior of test specimens, and the numerical results agreed well with the test data. The verified finite element model was extended to analyze the influences of the number of GFRP layers on the top of decks and the height of vertical webs. Based on equivalent method and compatibility of shear deformation, the flexural and shear rigidities were estimated. Then, analytical solution for displacement of the slab-rib integrated Sandwich composite decks subjected to four-point load was derived out. Comparison of analytical and experimental results shows that the displacements can be precisely predicted by the present theoretical model.
\end{abstract}

\section{Introduction}

Fiber-reinforced polymer (FRP) sandwich composites consisted of two thin facesheets and low-density cores and have been successfully applied as bridge decks, bumps for anti-collision of piers, structural walls and roofs, etc. in civil infrastructure [1-4], due to their advantageous properties of light weight, high flexural strength and rigidity, and substantial resistance to corrosion. Compared with pultruded hollow FRP modules, foam-filled sandwich composites exhibit improvement on local buckling of the lamina and contribute to decreasing the stress concentration at the webflange joint [5]. Among their applications in bridges, FRP sandwiches used as decks in deck-girder bridges or as slabs are beneficial for maintenance purposes and convenience of the replacement of the bridge to accommodate traffic increment. In the case of reinforced concrete (RC) deck replacement, FRP sandwich slabs usually have high thickness to provide the required flexural rigidity. The behavior of FRP Sandwich decks is greatly influenced by the choice of cross section and materials.

The performance of constructed bridges with FRP Sandwich decks is of interest to the researchers and transportation agencies. Sharaf et al. [6] investigated the flexural behavior of GFRP-polyurethane foam sandwich panels with different foam densities. It was shown that the ultimate load and stiffness increased by $165 \%$ and $113 \%$, as the core density was doubled. However, significant relative horizontal slip occurred between the upper and lower skins, due to the shear deformation of foam core [6]. Chen and Davalos [7] studied the strength properties of the facesheet of sandwich composite panels with honeycomb core and 
developed an optimized facesheet configuration. They suggested that the compressive strength of the facesheet was more critical and controlled the design. The design and field testing of a GFRP corrugated-core sandwich bridge indicated that the dynamic effects were insignificant and this structure is a competitive short-span bridge alternative [8]. In order to improve the structural efficiency and decrease the deck weight, Osei-Antw et al. [9] designed a novel GFRP sandwich slab-bridge, in which the core consisted of highdensity and low-density balsa and a FRP arch. Although the performance of this bridge structure is much better than structures with uniform core, the complex configuration and fabrication obstruct its extensive application.

One of the most severe defects associated with sandwich composite decks is the face-core delamination. Many studies have been carried out to improve the debonding resistance. Mohamed et al. [10] compared the mechanical behaviors of GFRP sandwich structures with web-core, trapezoid, and polyurethane rigid foam. Their test results showed that specimens with trapezoid foam core had highest load carrying capacity under flexural loads and compression, due to the presence of shear layer. A similar approach of trapezoidalshaped polyurethane foam core was considered by Tuwair et al. [11], who found that the shear webs contributed significantly to delaying the delamination of the skins from the core. The numerical analysis of Mostafa et al. [12] showed that inserting shear keys between the GFRP facesheets and the PVC foam core would improve the shear resistance of the sandwich panels, and the panels with uniaxial shear keys had higher shear strength than the panels with bi-axial shear keys. This is because the shear keys cause the loss of the solidarity of the bulk materials at the foam surface. Reis and Rizkalla [13] investigated the mechanical behavior of 3-dimensional (3D) GFRP sandwich panels and found that increasing the density of through-thickness fibers resulted in decreasing the tensile strength of the facesheets significantly, due to the waviness among the fibers in the perpendicular direction.

Although significant advancements have been made on FRP sandwich composites over the last two decades, bigger tolerance occurs in the hand layup sandwiches than in pultruded profiles. Furthermore, the intricate connecting details in deck-girder bridges are more challenging than the integrated structures $[14,15]$. To decrease the number of connections and improve the overall performance of composite decks, this work aims to develop a slab-rib integrated composite sandwich deck. The mechanical properties of both the composite and foam materials are optimally designed for flexural loads. Flexural tests have been conducted on nine slab-rib integrated sandwich decks with GFRP skins and polyurethane foam core. FRP layers, foam densities, horizontal and vertical webs, and cross beams were varied to study the deck behavior. A 3D finite element (FE) model is constructed, and the results are compared with the experimental data. The FE model was further used to investigate the influence of height of vertical webs and thickness of FRP skin in the compression region. Moreover, based on equivalent method and compatibility of shear deformation, the flexural and shear rigidities of integrated sandwich decks were obtained. Then, Timoshenko
Beam Theory (TBT) was applied to calculate the deformations of sandwich decks under flexural loads. Comparisons of analytical and experimental results are presented and discussed.

\section{Slab-Rib Integrated Bridge Deck Systems}

2.1. Description of the System Geometry. The bridge deck system consists of a slab and two ribs (Figure 1). The ribs contribute to improving the longitudinal stiffness of the slab in traffic direction. The study of Fettahoglu [16] showed that localized high stress concentrations occurred in the slab with thickness less than $10 \mathrm{~mm}$ under wheel loads. Moreover, Eurocode 3 part 2 [17] suggests the ratio of distance between ribs to slab thickness $e / t$ is no more than 25 and the rib spacing $e$ is no more than $300 \mathrm{~mm}$ under wheel loads. Thus, the height of the foam core of slab is taken as $55 \mathrm{~mm}$ and the distance of foam core between the ribs is taken as $260 \mathrm{~mm}$. Because the height of ribs has more significant influence on the deformation the deck than the width of ribs, the width-to-height ratio of the foam core of the ribs is taken as 0.67 . The overall length and width of the slab foam are $2 \mathrm{~m}$ and $0.6 \mathrm{~m}$. The length of the rib foams is the same as that of slabs.

Five types of slab-rib integrated deck systems with the same overall dimension are designed to evaluate the effects of webs and cross beams, as shown in Figure 1: (1) without webs and cross beams; (2) with vertical webs; (3) with horizontal webs; (4) with vertical and horizontal webs; (5) with cross webs. For deck systems with cross beams, two different arrangements of cross beams are investigated: (1) located in the mid-span and supports and (2) located in the supports merely. Figure 1 shows the cross section and $3 \mathrm{D}$ sketches of the different types of deck systems.

The test specimens differed in terms of the number of glass fabric layers of the FRP facesheets (i.e., fiber volume percent), the vertical and horizontal webs, the cross beams, and the density of polyurethane foams. The thickness of all GFRP webs is $1.6 \mathrm{~mm}$. The cross beams are of the same width and height of foam cores as ribs.

2.2. Material Properties. The face skins and vertical and horizontal webs were fabricated using E-glass fabrics and vinyl ester resin. The fiber volume in both the longitudinal and circumferential portions is $1: 1$. Five tension coupons were tested according to ASTM D 638 [18]. Table 1 lists the tension properties of GFRP laminates. Two types of closedcell polyurethane foams, with density of $100 \mathrm{~kg} / \mathrm{m}^{3}$ and $150 \mathrm{~kg} / \mathrm{m}^{3}$, were used in this study. For each density, five cubic coupons with side length of $50 \mathrm{~mm}$ were tested in accordance with ASTM D C 365/C 365 [19], to obtain the compressive properties. Table 2 presents the measured properties of polyurethane foams.

\section{Experimental Program}

3.1. Specimen for Test. Nine specimens were prepared to study the flexural behavior of slab-rib integrated bridge decks with GFRP composite skins and polyurethane foam core. Table 3 lists the details of the test specimens. To make 


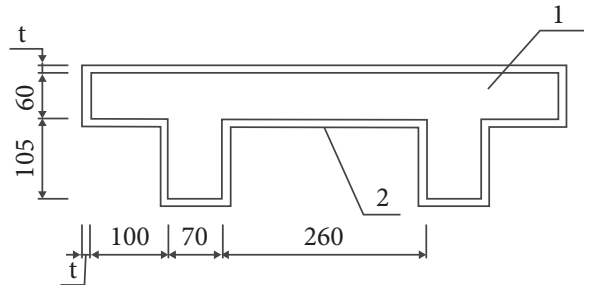

(a)

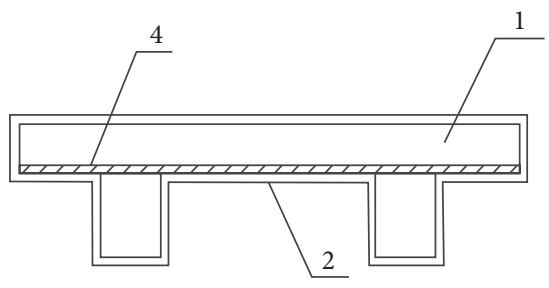

(c)

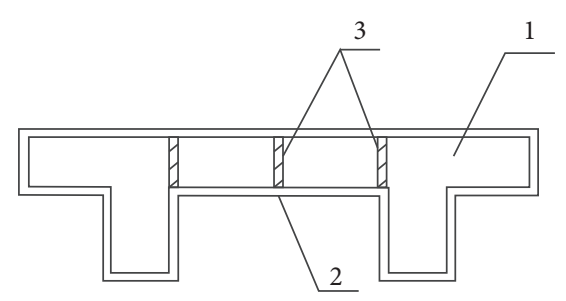

(b)

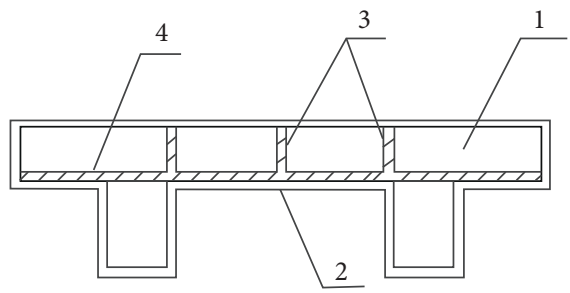

(d)

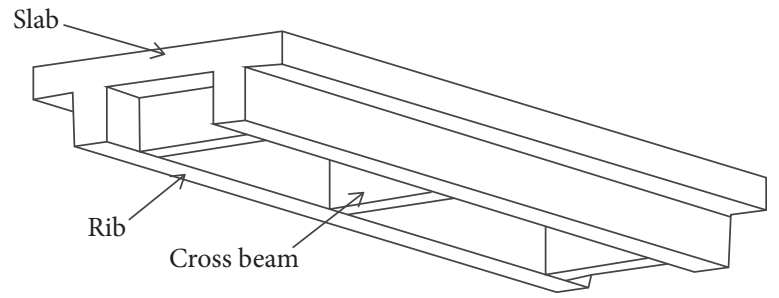

(e)

Figure 1: Configuration of slab-rib integrated bridge deck systems: (a) cross section of sandwich decks without webs, (b) cross section of sandwich decks with vertical webs, (c) cross section of sandwich decks with horizontal webs, (d) cross section of sandwich decks with vertical and horizontal webs, and (e) 3D view of decks with cross beams (1: foam core; 2: FRP skin; 3: vertical webs; 4: horizontal webs).

TABLE 1: Tensile properties of GFRP.

\begin{tabular}{lcc}
\hline Property & Value & e (\%) \\
\hline Tensile strength $(\mathrm{MPa})$ & 304 & 8.31 \\
Tensile modulus $(\mathrm{GPa})$ & 26 & 6.47 \\
Poisson's ratio & 0.22 & 6.57 \\
\hline
\end{tabular}

$e=$ coefficient of variation

the slab-rib structures (Figure 2), the foam panels were cut into separations for slabs, ribs, and diaphragms. Orthogonal grids $(25 \mathrm{~mm} \times 25 \mathrm{~mm} \times 2 \mathrm{~mm})$ were grooved and holes with diameter of $5 \mathrm{~mm}$ and depth of $2 \mathrm{~mm}$ were drilled on the surface of the foam panels to enhance the bonding strength between the GFRP skin and foam core. Before wrapping with bidirectional glass fabric layers, the foam separations were assembled into slab-rib structures. Then, vacuumassisted resin infusion process was used to fabricate the specimens.

3.2. Experimental Setup. The specimens were tested under four-point flexural loads acted at about one-third intervals of the span. The experimental setup consists of a $500 \mathrm{kN}$ load cell which transfers the load to two load heads using a spreader steel beam. The deflections at midspan and supports were measured using linear variable displacement transducers (LVDTs). The typical test setup of four-point simply supported decks is shown in
Figure 3. In order to monitor stress state of the mid-span cross section, 12 strain gages (gauge length $10 \mathrm{~mm}$ ) were bonded to the top, side, and bottom surfaces of the test specimens, as shown in Figure 4 . Static loads were applied at a rate of $2 \mathrm{~mm} / \mathrm{min}$. All the specimens were tested to a point where the loading could not be increased anymore.

\section{Experimental Results and Discussion}

4.1. Failure Modes. Figure 5 provides a summary of the typical failure modes. The failures of specimens without webs and cross beams (i.e., S2D, S4D, and S6D) were governed by debonding of GFRP facesheets from the foam core, outward facing wrinkled, tearing of facesheets in the corner of slabs near the loading points, and shear cracks that propagated from the narrow side of slabs to ribs. Moreover, transverse cracks appeared on the back of slabs due to the shear failure of GFRP facesheets under the loading points. The specimens with different layers of GFRP facesheets exhibited similar failure modes. Contrary to expectations, the specimen with lower foam density has much smaller debonding area on the top facesheets than the specimens with higher foam density. This may be attributed to the lower rigidity of foams with smaller density which allows compatible deformation under debonding loads. 
TABLE 2: Compressive properties of PU foams.

\begin{tabular}{|c|c|c|c|c|}
\hline Foam density $(\mathrm{kg} / \mathrm{m} 3)$ & Compressive strength (MPa) & $e(\%)$ & Compressive modulus (MPa) & $e(\%)$ \\
\hline 100 & 0.767 & 6.57 & 15.527 & 5.27 \\
\hline 150 & 1.566 & 3.57 & 37.64 & 6.08 \\
\hline
\end{tabular}

$e=$ coefficient of variation.

TABLE 3: Summary of test matrix and results.

\begin{tabular}{lcccccc}
\hline Specimen & $P(\mathrm{kN})$ & $P_{1}(\mathrm{kN})$ & $P_{1} / P$ & $\delta_{1}(\mathrm{~mm})$ & $\delta_{2}(\mathrm{~mm})$ & $\delta_{2} / \delta_{1}$ \\
\hline S2D & 34.35 & 31.64 & 0.92 & 26.55 & 24.95 & 0.94 \\
S4D & 68.66 & 72.84 & 1.06 & 33.27 & 31.08 & 0.83 \\
S6D & 107.70 & 109.01 & 1.01 & 33.79 & 29.73 & 0.88 \\
S4d & 91.15 & 87.67 & 0.96 & 38.95 & 35.26 & 0.91 \\
S4DV & 109.25 & 117.18 & 1.07 & 38.89 & 34.53 & 0.89 \\
S4DH & 68.73 & 71.23 & 1.04 & 31.46 & 27.15 & 0.86 \\
S4DVH & 115.61 & 121.05 & 1.05 & 45.68 & 39.96 & 0.88 \\
S4DT2 & 87.19 & 92.23 & 1.06 & 38.52 & - & - \\
S4DT3 & 65.56 & 70.64 & 1.08 & 29.80 & - & - \\
\hline
\end{tabular}

In the first column, the letters $d$ and $D$ mean the densities of synthetic foams are $100 \mathrm{~kg} / \mathrm{m} 3$ and $150 \mathrm{~kg} / \mathrm{m} 3$, respectively, the letters $V$ and $H$ mean the specimens have vertical and horizontal webs, the letter $T$ means the specimens have cross beams, the first number means the number of FRP layers of the GFRP skins, and the numbers 2 and 3 mean the number of cross beams, respectively. In the first row, $P$ is the tested ultimate load, and $P_{1}$ is the ultimate load obtained from FE model; $\delta 1$ is the tested maximum deformation, and $\delta 2$ is the calculated deformation from equation (17).

The specimen with horizontal webs has similar failure pattern with the specimen without webs, while the specimen with vertical webs showed full bond between skins and the cores under vertical loads. Crushing of the top skin and foam at the loading points dominated the failure modes of specimens with vertical webs. This suggests that adding vertical webs is a reliable method to prevent the debonding of facesheets and foam core.

The specimen with cross beams at the supports exhibited shear failure of foam and crushing of skins at the loading point and no obvious debonding of the skins was observed. For specimen with 3 cross beams at the supports and midspan, the top face was multi-waved wrinkled due to the debonding of facesheets. The additional cross beam in the mid-span is unable to play a positive role in this structure.

4.2. Load-Displacement Curves. Load versus mid-span displacement measured from the test specimens is presented in Figure 6, along with a discussion on the effect of various parameters on the structural behavior of the slab-rib decks. All the test specimens exhibited similar load-displacement profiles. The load increased almost linearly up to the maximum and then suddenly decreased when the GFRP facesheets on the top of slabs were crushed near the loading points. After that, the load increased until a new crack formed in the inner foams.

It is obvious that the rigidity of slab-rib decks was accordingly increased as the layer number of GFRP skins increased. Very thin woven fabric layers may result in premature failure of the facesheets in the loading point. Indeed, the ultimate loads of specimens with 4 and 6 layers of GFRP skins are two and three times as much as that of specimens with 2 layers of GFRP skins, respectively, and the ultimate deformation increased by about $25 \%$. On the contrary, the ultimate load of specimen with foam density of $100 \mathrm{~kg} / \mathrm{m}^{3}$ was $33 \%$ higher than that of specimen with foam density of $150 \mathrm{~kg} / \mathrm{m}^{3}$. This is because debonding of the top facesheets and local buckling of GFRP dominate the failure modes of specimens with higher foam density, while the debonding of facesheets does not extensively occur in the specimens with lower foam density.

The specimen with horizontal webs has similar ultimate load and slope of linear phase of load-displacement curve as specimens without webs, while the ultimate load of the specimen with vertical webs is $59 \%$ higher than the specimen without webs. The specimen with horizontal and vertical webs has a little higher ultimate load (6\%) than the specimen with vertical webs. This suggests that adding vertical webs in slab-rib sandwich decks is a more reliable method to improve the debonding of facesheets and enhance the load carry capacity than adding horizontal webs.

By comparing the responses of specimens with and without cross beams, it can be concluded that adding 2 cross beams at the supports contributes to increasing the ultimate loads by $27 \%$, while adding 3 cross beams at the supports and mid-span is not useful to enhance the ultimate loads and rigidity. The additional cross beam in the mid-span tends to prevent the transverse deformation of the ribs, and then the incompatible deformation occurred between the foam core and skins, resulting in large area debonding of facesheets.

4.3. Strain Distributions. Figure 7 shows the typical midspan strain distribution through the depth of slab-rib sandwich decks. For specimen without webs and cross beams, the longitudinal strain distributions remained flat up to $80 \%$ of ultimate load and the strains increased almost linearly with increasing load. The specimens with additional horizontal webs and cross beams at supports have similar strain distribution to specimens without webs and cross beams. However, the specimens with vertical webs or two cross beams behaved nonlinearly during loading. The strains of the bottom facesheets of specimen with three cross beams exhibited a bias to large value. This is the reason that the specimen with three cross beams is more prone to failure than others.

\section{FE Model Construction}

The finite element software ABAQUS has been successfully used to simulate the performance of steel bridge deck pavement with fiber-reinforced epoxy resin-modified asphalt [20]. In this paper, a 3D FE model has been developed using Abaqus Explicit to analyze the flexural properties of 


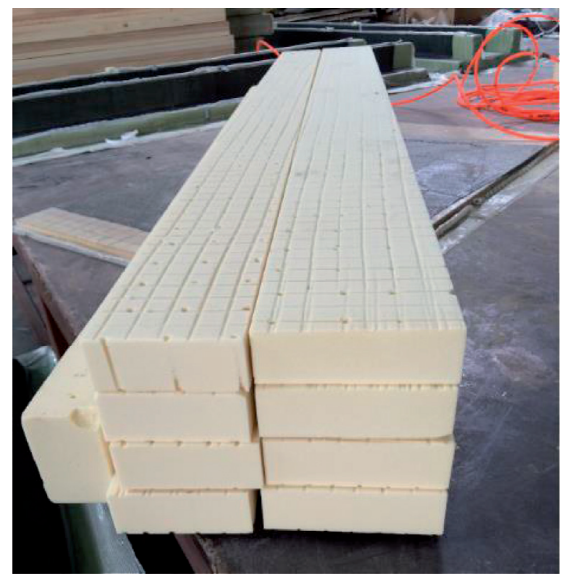

(a)

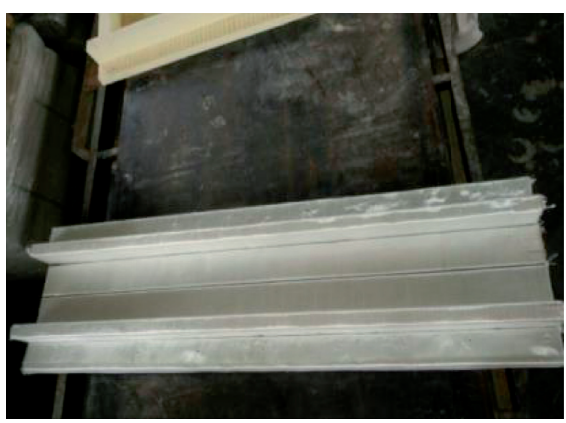

(d)

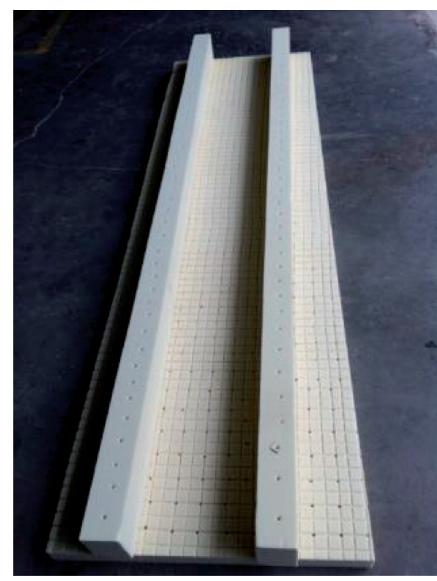

(b)

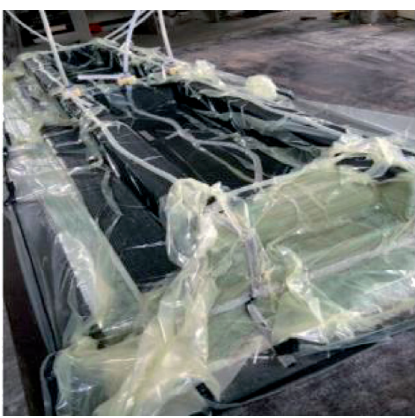

(e)

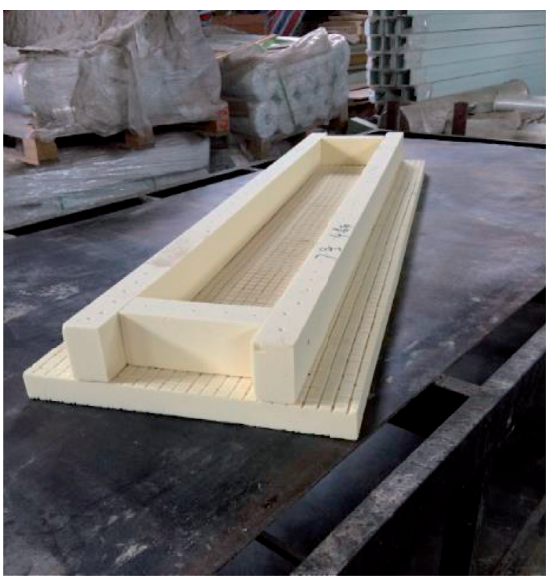

(c)

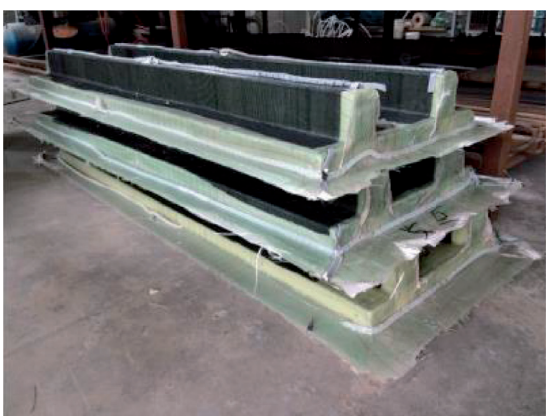

(f)

FIGURE 2: Fabrication procedure of test specimens: (a) the separation foams which have been grooved and drilled on the surface, (b) assembling foams of slab and ribs, (c) assembling diaphragms, (d) wrapping the assembled foams with GFRP, and (e, f) vacuum-assisted resin infusion process.

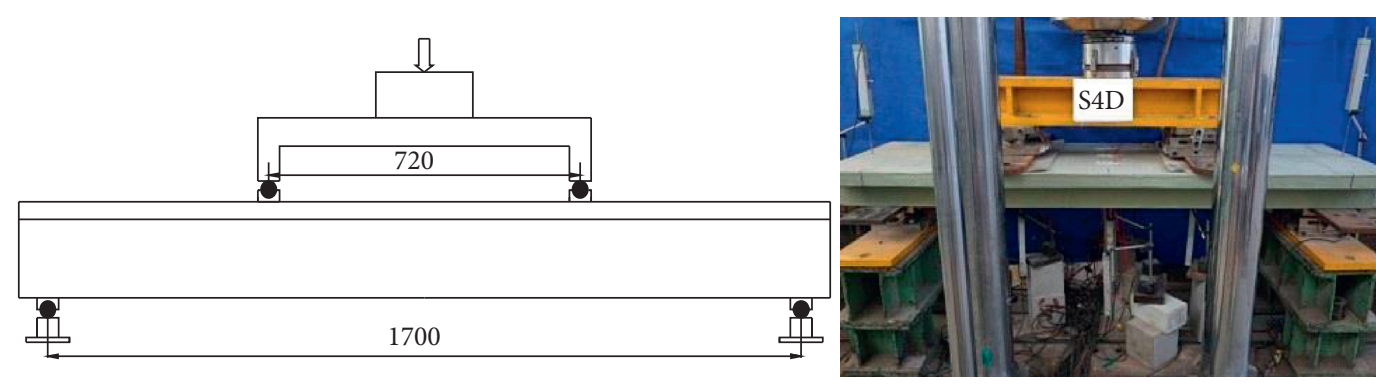

FIgURE 3: Test setup (units: $\mathrm{mm}$ ).

\begin{tabular}{rl|}
\hline & $\square$ \\
& $=2$ \\
& $\square 3$ \\
\hline
\end{tabular}

(a)

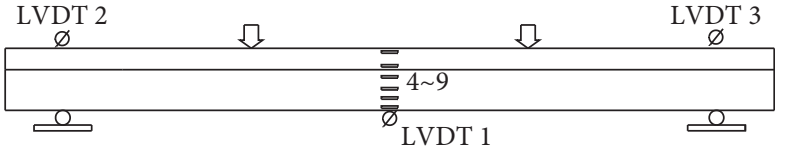

(b)

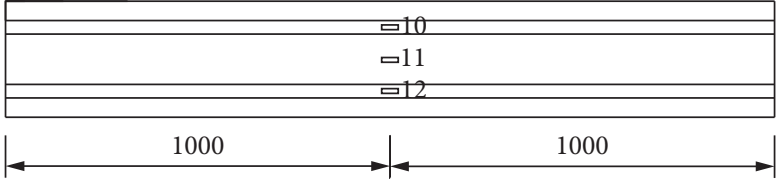

(c)

FIGURE 4: Locations of LVDTs and strain gauges: (a) plane view from the top, (b) side view, and (c) plane view from the bottom (units: mm). 


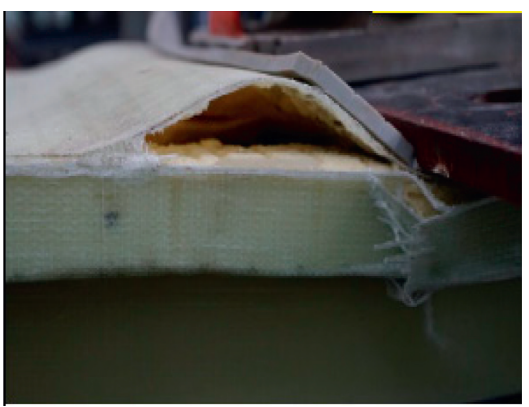

(a)

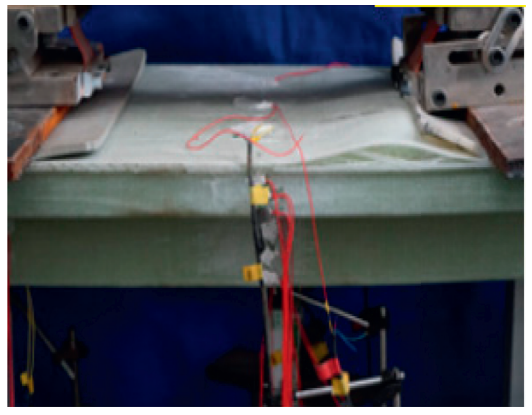

(d)

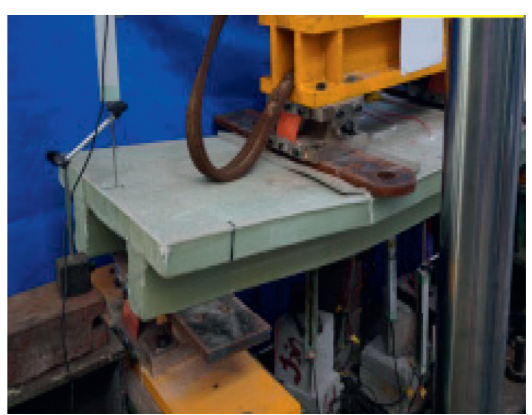

(g)

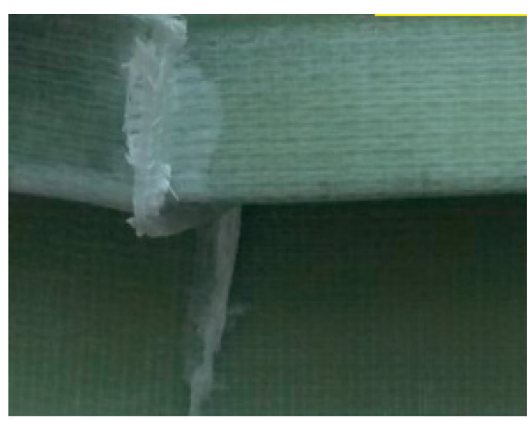

(j)

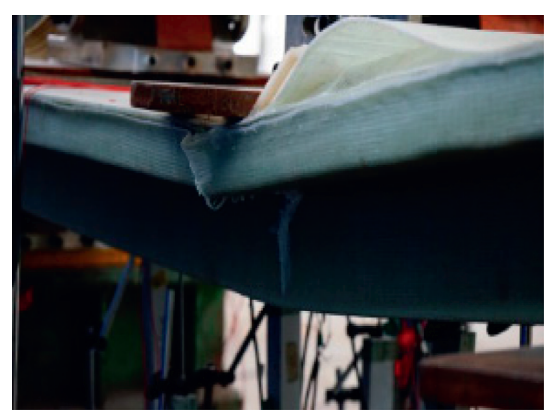

(b)

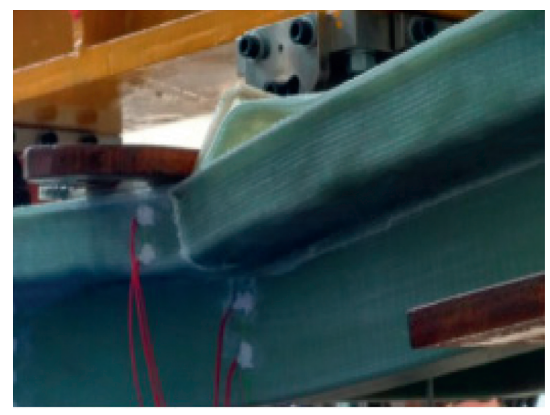

(e)

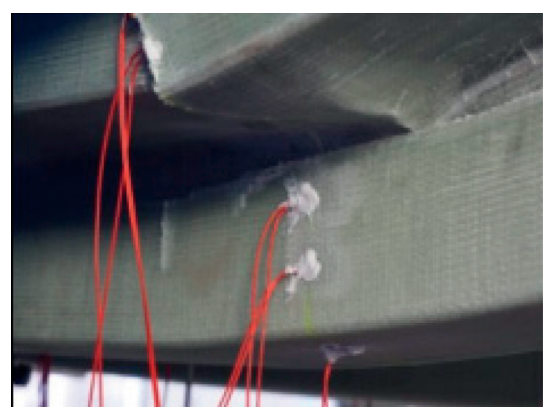

(h)

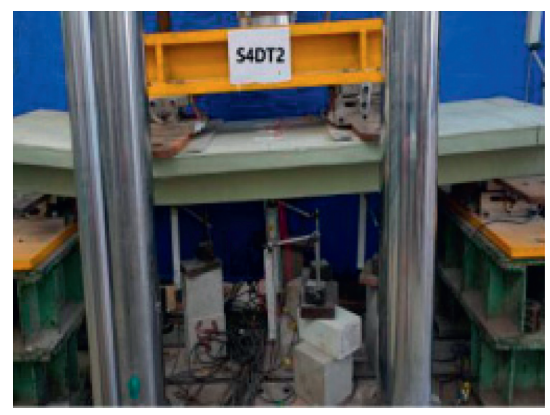

(k)

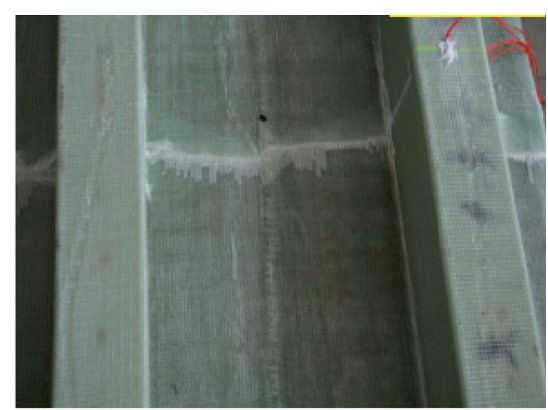

(c)

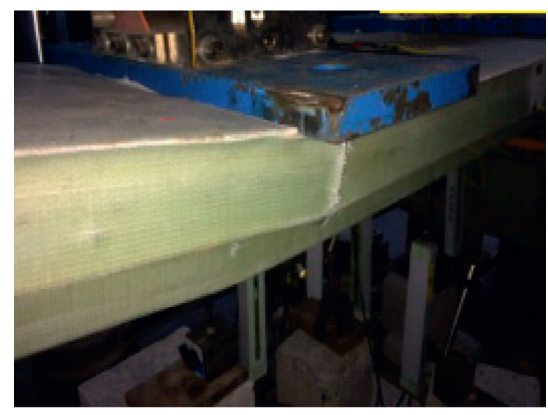

(f)

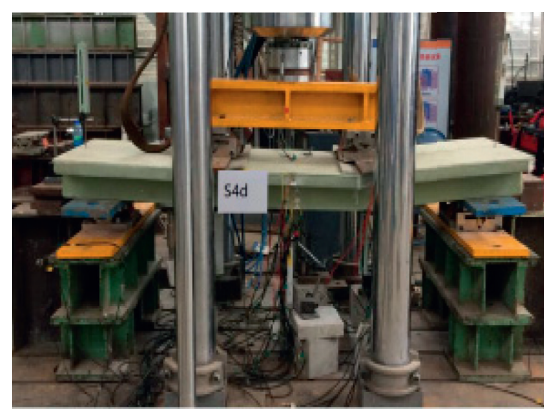

(i)

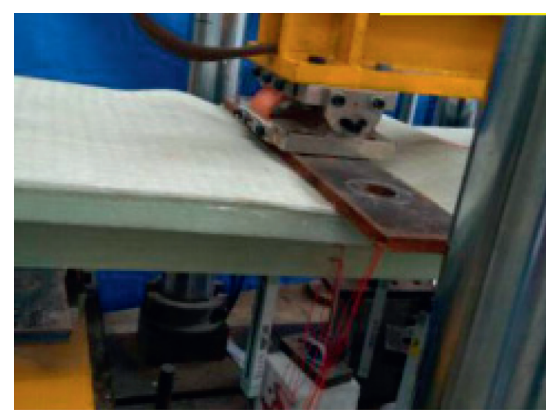

(1)

Figure 5: Failure modes. (a) S2D. (b) S4D. (c) S4D. (d) S6D. (e) S4DH. (f) S4DV. (g) S4DVH. (h) S4DV. (i) S4d. (j) S4d. (k) S4DT2. (l) S4DT3.

slab-rib integrated decks. The material properties of both GFRP and polyurethane foam were obtained from coupon test results. The GFRP facesheets and webs are assumed to behave in a linear elastic manner, and the Hashin criterion is used to predict the failure of GFRP. Hashin failure criteria has been successfully applied to predict failure and postfailure of anisotropic fiber-reinforced materials [21]. The material property of polyurethane foam is specified in the elastic-plastic model, in which the plasticity modulus is taken as $50 \%$ of elastic modulus.

GFRP facesheets and webs are modeled by S4R shell element, while polyurethane foam is modeled by C3D8R brick element. The test specimens are simply supported. Surface-to-surface contact elements are used to simulate the interface between GFRP and foam core. This type of contact considers slip and separation. Hence, slip/debonding is 


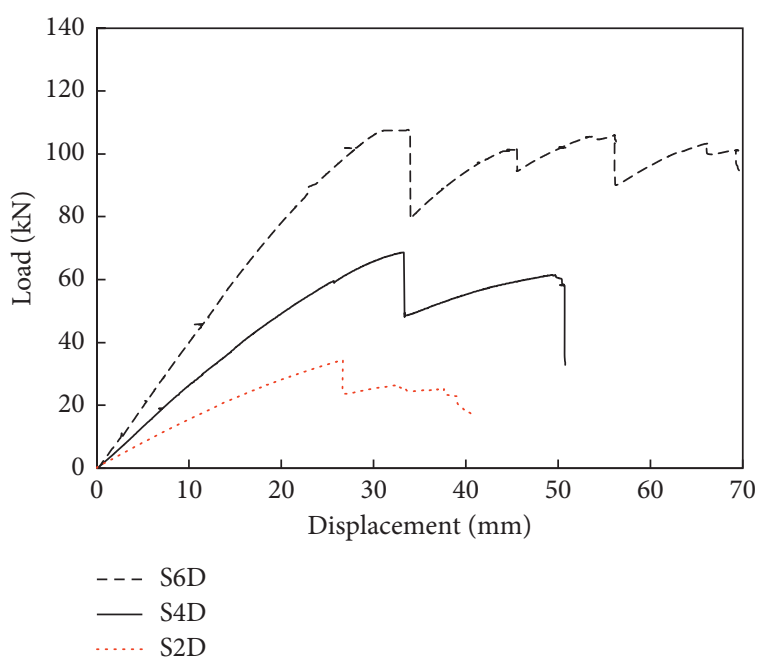

(a)

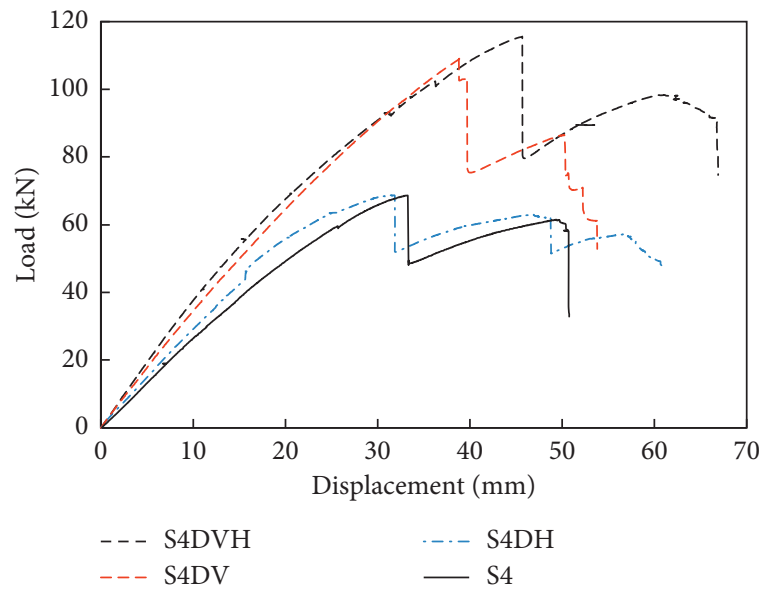

(c)

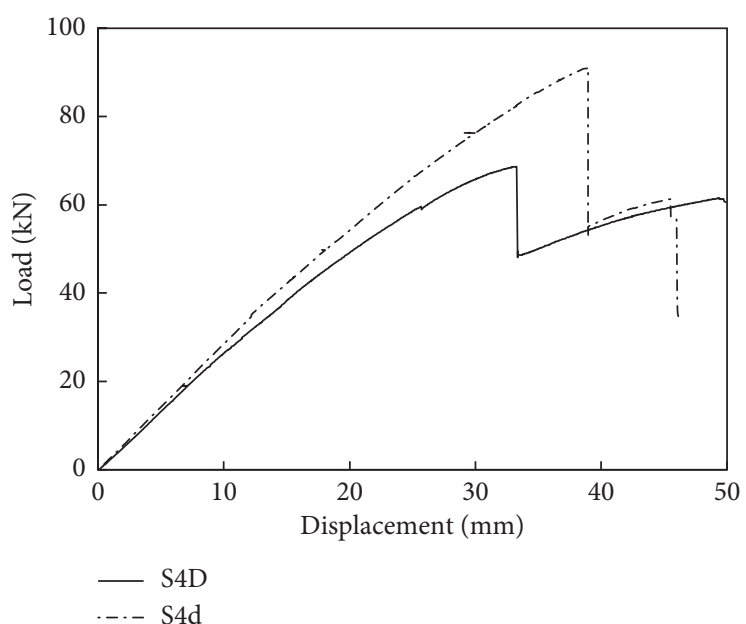

(b)

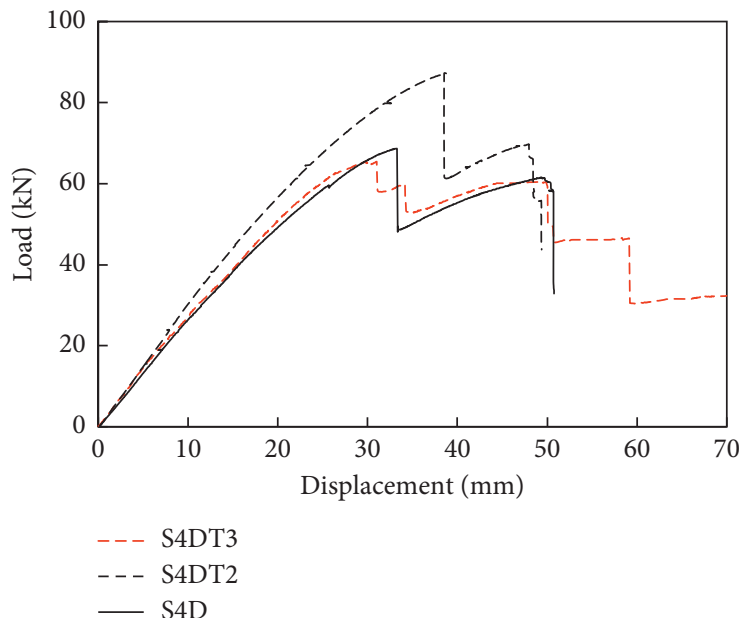

(d)

Figure 6: Load-displacement responses.

displayed if either occurs between the GFRP surface and foam surface. The friction coefficient is taken as 0.3 for the contact surface of GFRP and foam core.

5.1. Comparison of Numerical and Experimental Results. The simulated failure modes of typical specimens are shown in Figure 8 . The FE model successfully captures the local buckling of the top facesheets of the test specimens. The Mises stress of S4DV at the loading points was smaller than those of specimens S4D and S4DH, and the debonding area of GFRP skin of S4DV was much smaller than those of specimens S4D and S4DH. For specimen S4DT3, stress concentration occurred in the intersection of ribs and the cross beam in the mid-span under flexural loads, resulting in incompatibility deformation of the cross beam in the midspan.

The comparison of numerical and experimental loaddisplacement curves of the test specimens is shown in Figure 9. The numerical curves in Figure 9 show that the model offered reasonable trend with the test data; i.e., FE analysis is capable of capturing the overall shapes of the tested load-displacement histories. Table 3 reveals that the numerical ultimate loads are in good agreement with the experimental values.

The finite element analysis is extended to study the effects of the height of vertical webs and the thickness of GFRP skins on the compressive region which are not tested in the experimental program.

5.2. Influence of the Height of Vertical Webs. The experimental results indicated that the existing vertical webs contribute to improving the debonding of facesheets from foam core. To investigate the influence of geometry of vertical webs, three different heights of vertical webs (i.e., $80 \mathrm{~mm}, 105 \mathrm{~mm}$, and $125 \mathrm{~mm}$ ) are tried on S4D specimens, respectively. Figure 10(a) shows load-displacement curves of S4D specimens with different height of vertical webs under flexural loads. Increasing the heights of vertical webs from $80 \mathrm{~mm}$ to $105 \mathrm{~mm}$ and $125 \mathrm{~mm}$ resulted in $9 \%$ and $27 \%$ enhancement of ultimate loads, and $17 \%$ and $35 \%$ enhancement of rigidities. 

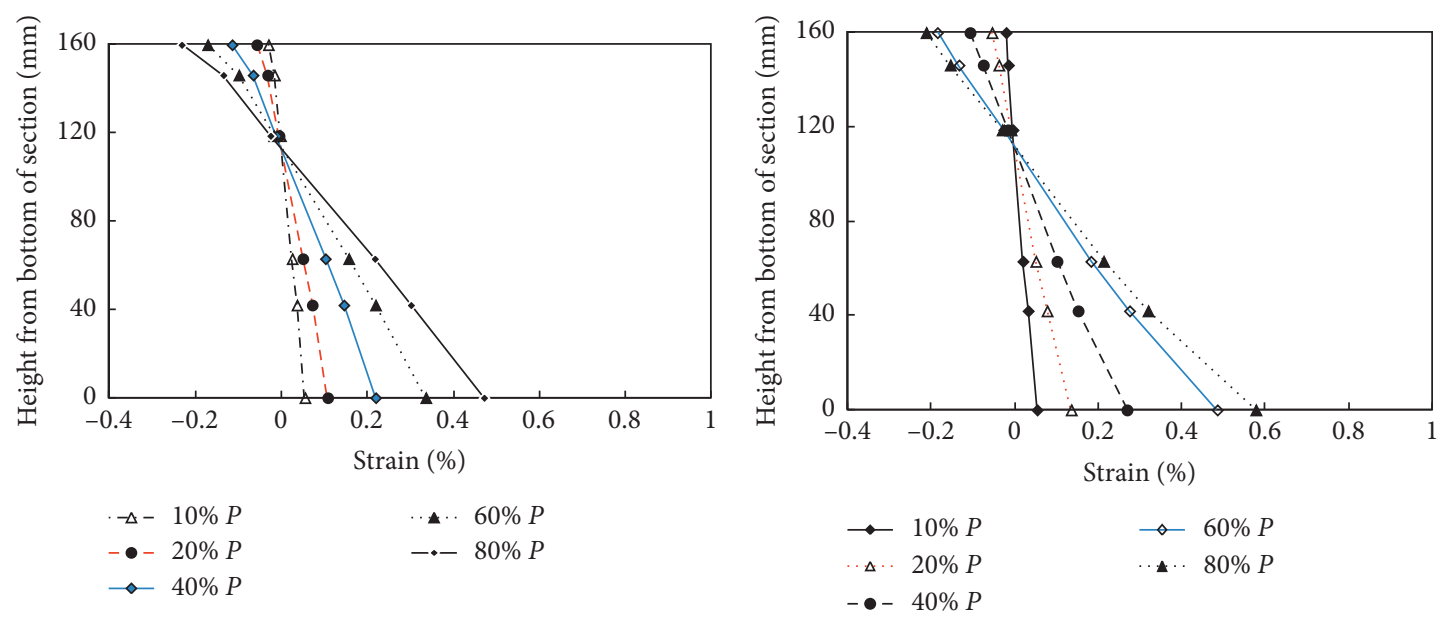

(a)

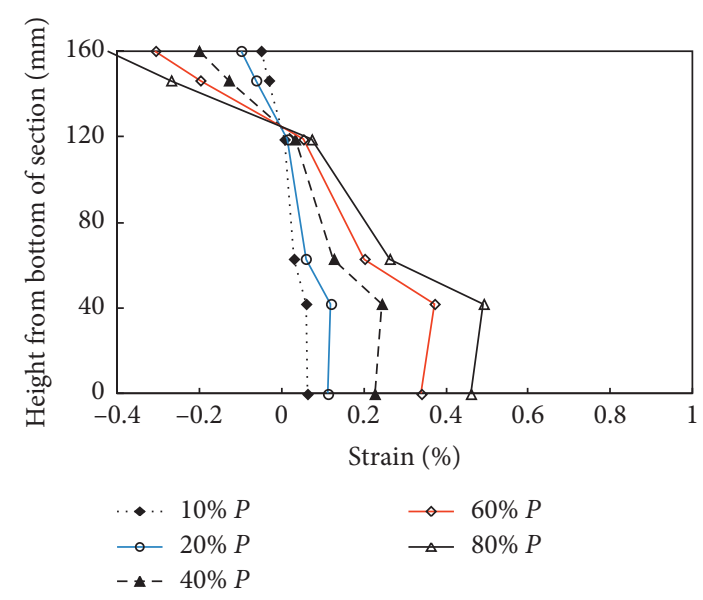

(c)

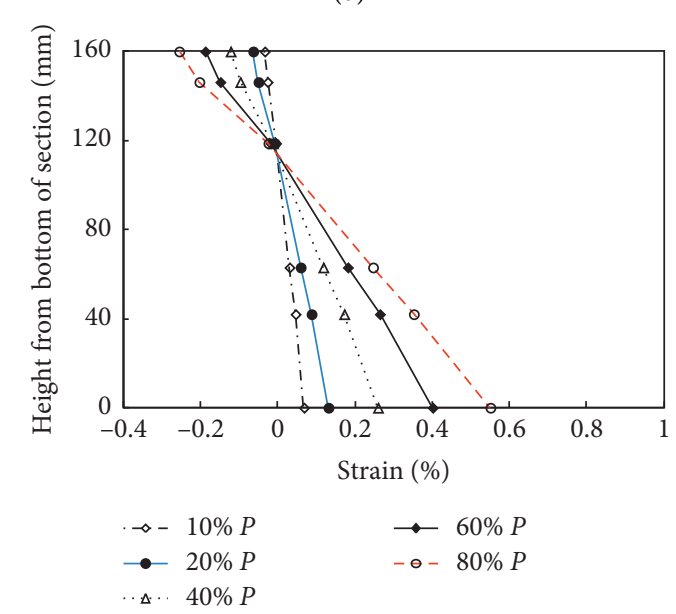

(d)

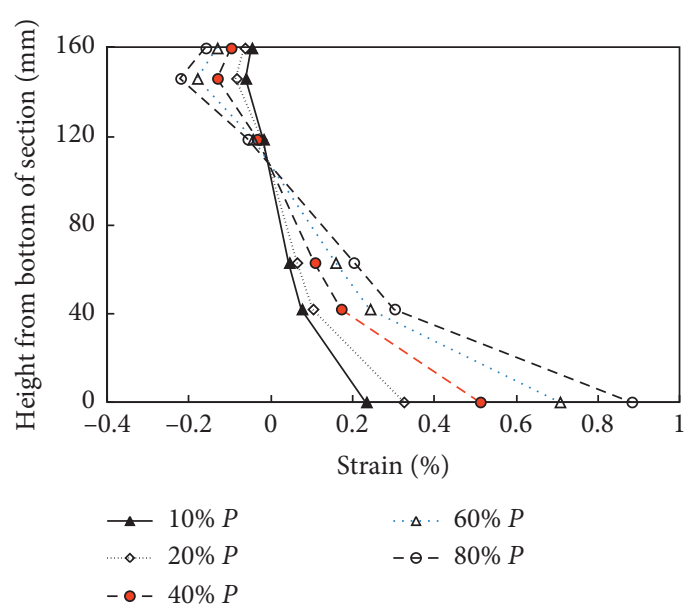

(e)

Figure 7: Typical strain distribution curves across the depth at mid-span: (a) S4D, (b) S4DH, (c) S4DV, (d) S4DT2, and (e) S4DT3.

5.3. Influence of GFRP Layers on the Compressive Region. The experimental results indicated that local buckling tends to occur in the thin facesheets on the compressive region of sandwich decks. To investigate the influence of GFRP layers on the top of decks, three different layers (i.e., 4, 6, and 8) are tried on the top of S4D specimens, respectively. Figure 10(b) shows load-displacement curves of S4D specimens with different GFRP layers on the top under flexural loads. Increasing layers of GFRP on the top from 4 to 6 and 8 resulted in $15 \%$ and $32 \%$ enhancement of ultimate loads, and $7 \%$ and $16 \%$ enhancement of rigidities. 


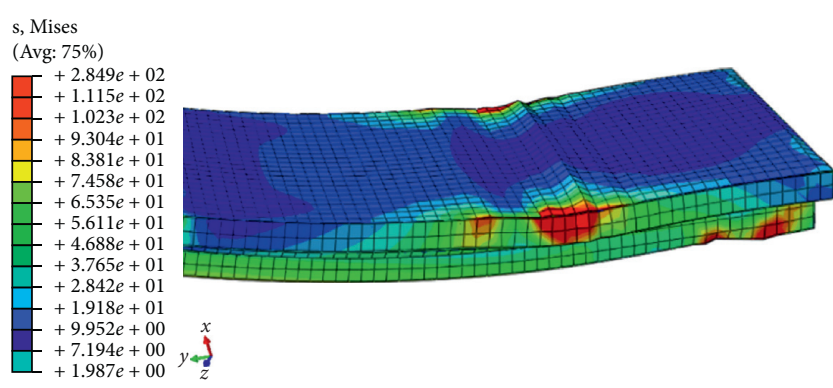

(a)

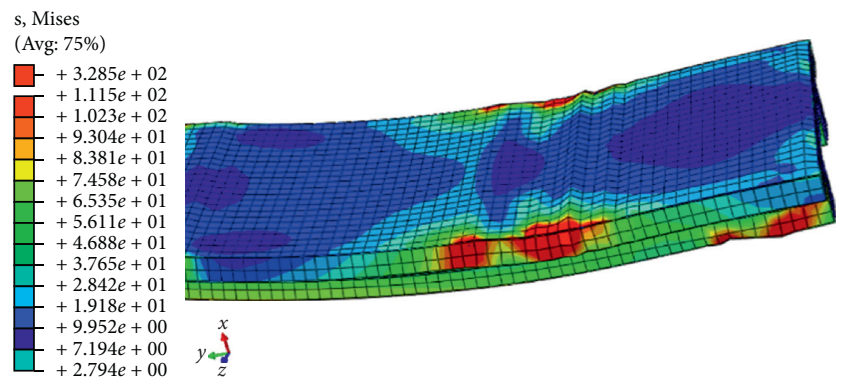

(c)

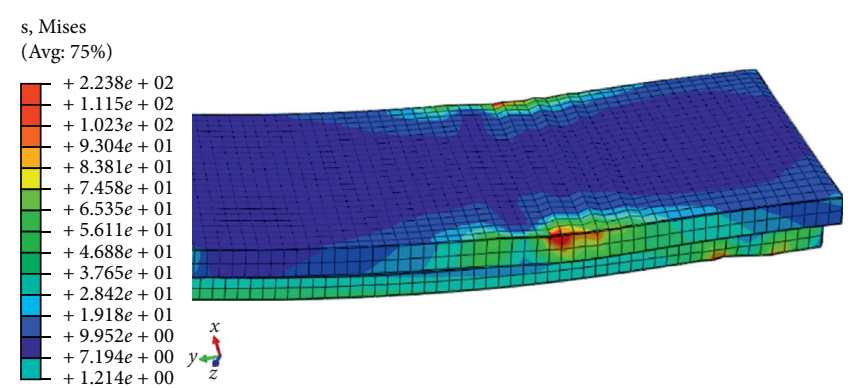

(b)

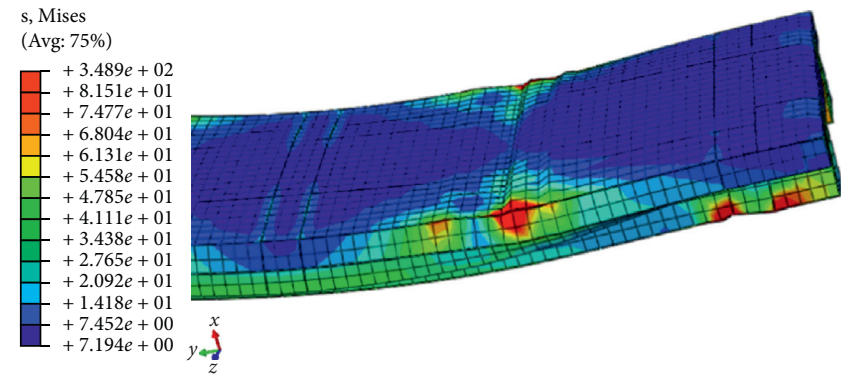

(d)

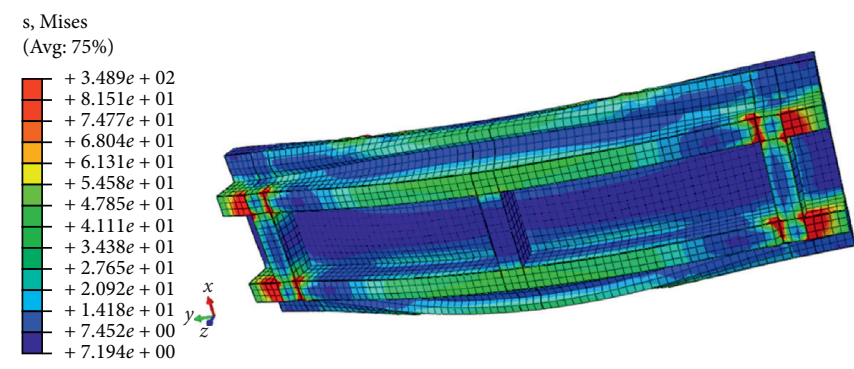

(e)

Figure 8: Simulated Mises stress contour at failure (unit: MPa): (a) S4D; (b) S4DV; (c) S4DT3 (top surface); (d) S4DT3 (bottom surface).

The simulated results indicated that the height of vertical webs had significant effect on the rigidity, while the layer number of GFRP on the compressive region had significant effect on the load carrying capacities.

\section{Theoretical Calculations}

6.1. Prediction of Flexural Rigidity. To simplify the calculation, the equivalent method is used to predict the flexural rigidity of slab-rib integrated sandwich decks, in which the deck rigidity $(E I)_{\mathrm{eff}}$ is directly computed based on the transformed section technique. The transformed section is obtained by replacing core material with an equivalent amount of FRP. The cross section of the integrated composite decks is shown in Figure 11(a). The transformation factor $\alpha$ is determined by the elastic modulus ratio of foam core to FRP facesheets.

$$
\lambda=\frac{E_{c}}{E_{f}},
$$

where $E_{\mathrm{c}}$ and $E_{f}$ are Young's moduli of foam core and FRP, respectively.

The distances of centroids of foam core and integrated decks to the bottom of decks $y_{c 0}$ and $y_{c}$ are given as

$$
\begin{aligned}
& y_{c 0}=\frac{b h_{1}\left(h_{2}+0.5 h_{1}\right)+a h_{2}^{2}}{b h_{1}+2 a h_{2}}, \\
& y_{c}=\frac{\left(a+2 t_{f}\right) h_{2}^{2}+\left(b+2 t_{f}\right)\left(h_{1}+2 t_{f}\right)\left(h_{2}+0.5 h_{1}+t_{f}\right)}{\left(b+2 t_{f}\right)\left(h_{1}+2 t_{f}\right)+2\left(a+2 t_{f}\right) h_{2}},
\end{aligned}
$$

where $a$ and $b$ are the width of core of slabs and ribs, respectively, $h_{1}$ and $h_{2}$ are the height of core of slabs and ribs, respectively, and $t_{f}$ is the thickness of facesheets.

The equivalent core height $h_{\mathrm{eq}}$ is

$$
h_{\mathrm{eq}}=\frac{\lambda\left(b h_{1}+2 a h_{2}\right)}{b} \text {. }
$$




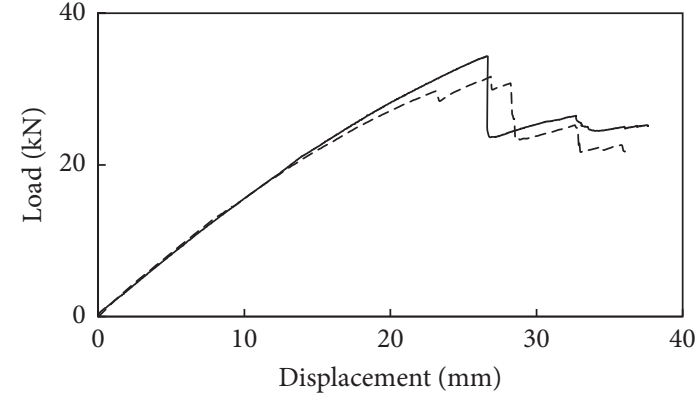

- Experimental curve - . - FEM curve

(a)

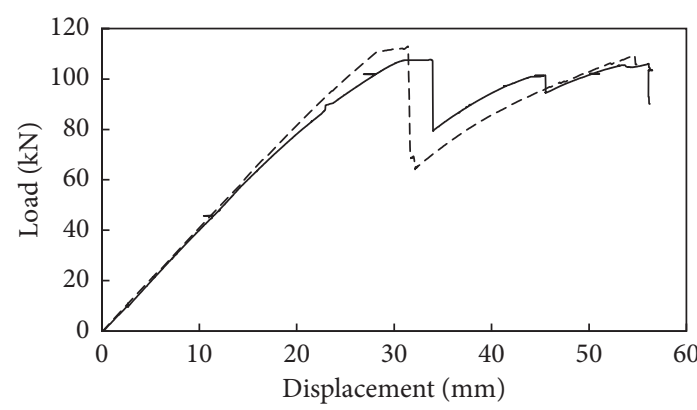

_ Experimental curve

- - - FEM curve

(c)

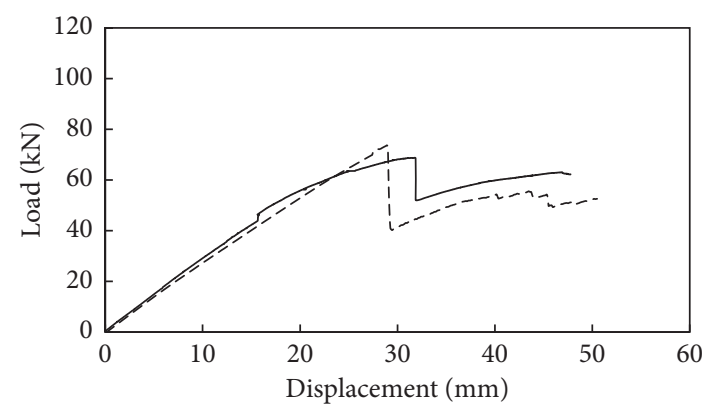

- Experimental curve

- - - FEM curve

(e)

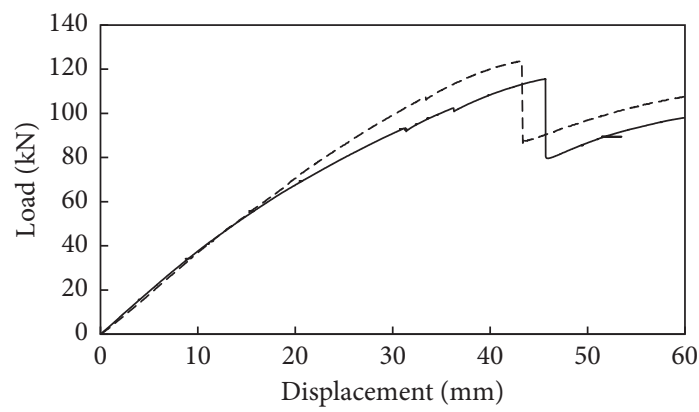

- Experimental curve

- . - FEM curve

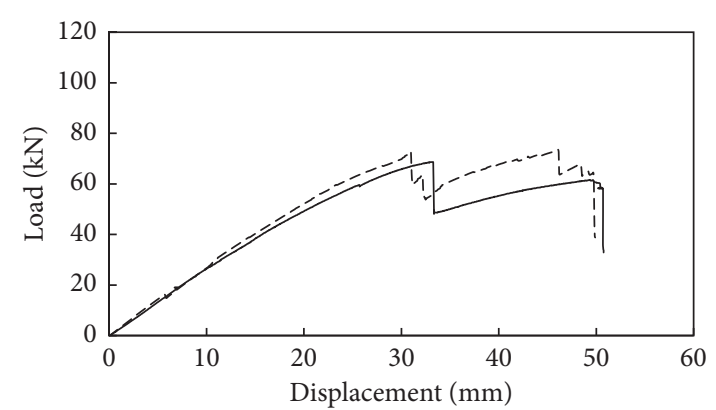

- Experimental curve - - - FEM curve

(b)

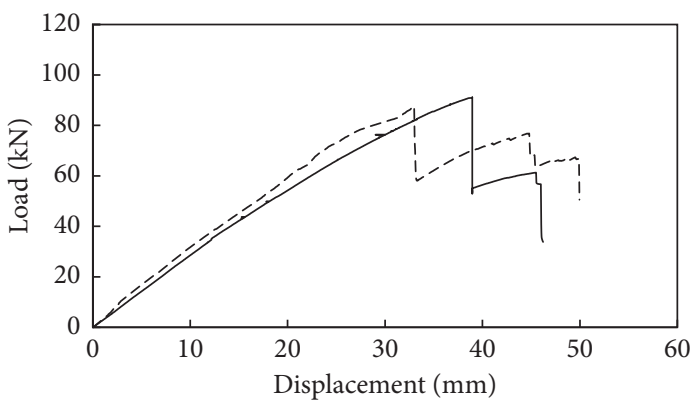

_- Experimental curve

- - - FEM curve

(d)

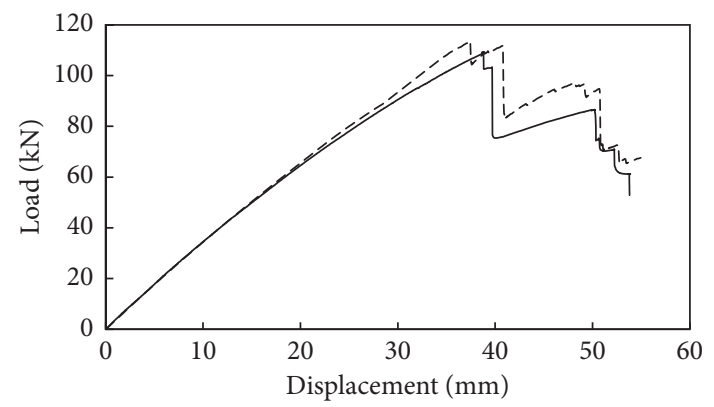

- Experimental curve

- - - FEM curve

(f)

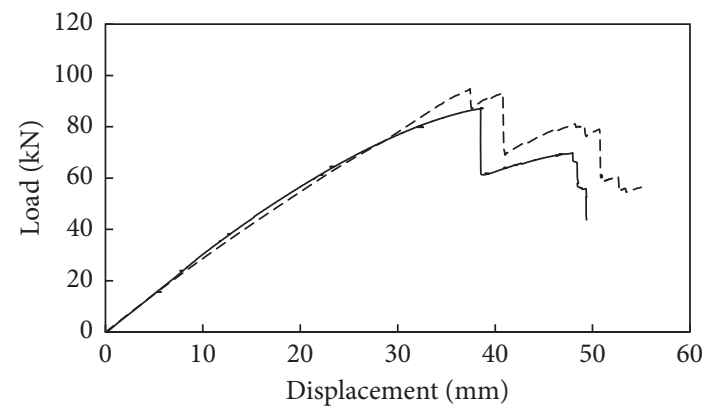

- Experimental curve

- - FEM curve

(g)

(h)

Figure 9: Continued. 


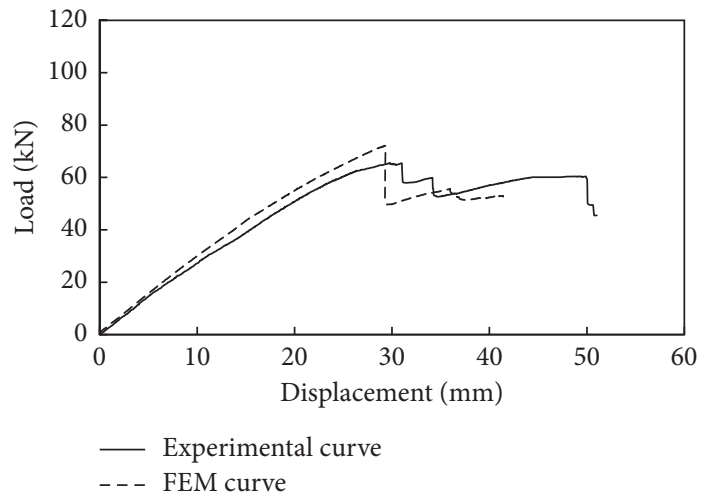

(i)

Figure 9: Comparison of numerical and experimental load-displacement curves for (a) S2D, (b) S4D, (c) S6D, (d) S4d, (e) S4DV, (f) S4DH, (g) S4DVH, (h) S4DT2, and (i) S4DT3.

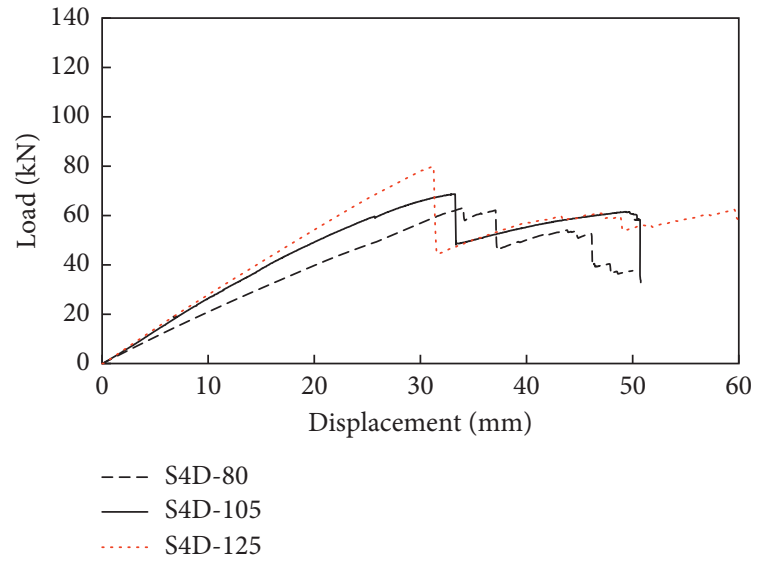

(a)

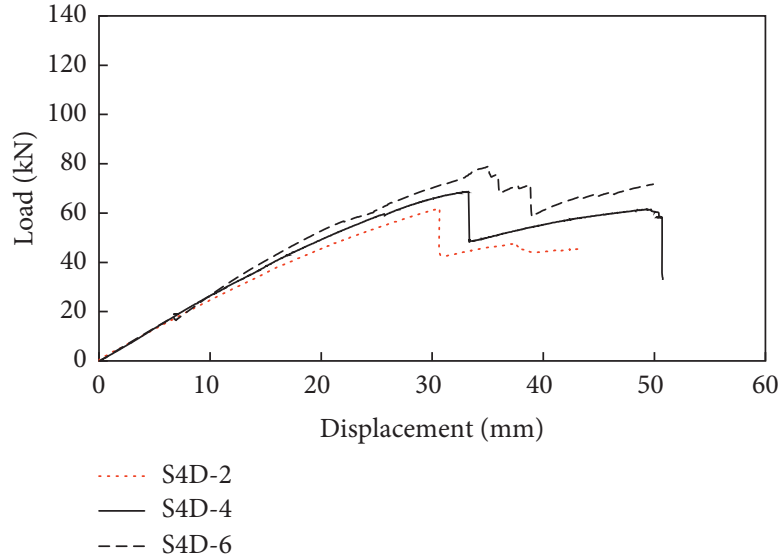

(b)

FIGURE 10: Simulated load-displacement curves of S4D: (a) with different height of vertical webs and (b) with different GFRP layers on the compressive region.

The inertia of FRP facesheets, webs, and the equivalent moment of inertia of foam core are given as

$$
\begin{aligned}
I_{f} & =\left(\frac{b_{1} t_{f}^{3}}{12}+b_{1} t_{f} d_{1}^{2}\right)+2\left(\frac{b_{2} t_{f}^{3}}{12}+b_{2} t_{f} d_{2}^{2}\right)+\left(\frac{b_{3} t_{f}^{3}}{12}+b_{3} t_{f} d_{3}^{2}\right)+2\left(\frac{t_{f} h_{1}^{3}}{12}+h_{1} t_{f} d_{4}^{2}\right)+4\left(\frac{t_{f} h_{2}^{3}}{12}+h_{2} t_{f} d_{5}^{2}\right), \\
I_{w v} & =n\left[\frac{t_{w} h_{1}^{3}}{12}+t_{w} h_{1}\left(h_{2}+0.5 h_{1}+t_{f}-y_{c}\right)^{2}\right] \\
I_{w h} & =\frac{b t_{w}^{3}}{12}+b t_{w}\left(y_{c}-t_{f}-h_{2}-0.5 t_{w}\right)^{2}, \\
I_{c} & =\frac{b h_{\mathrm{eq}}^{3}}{12}+b h_{\mathrm{eq}}\left(y_{c 0}-y_{c}\right)^{2}
\end{aligned}
$$




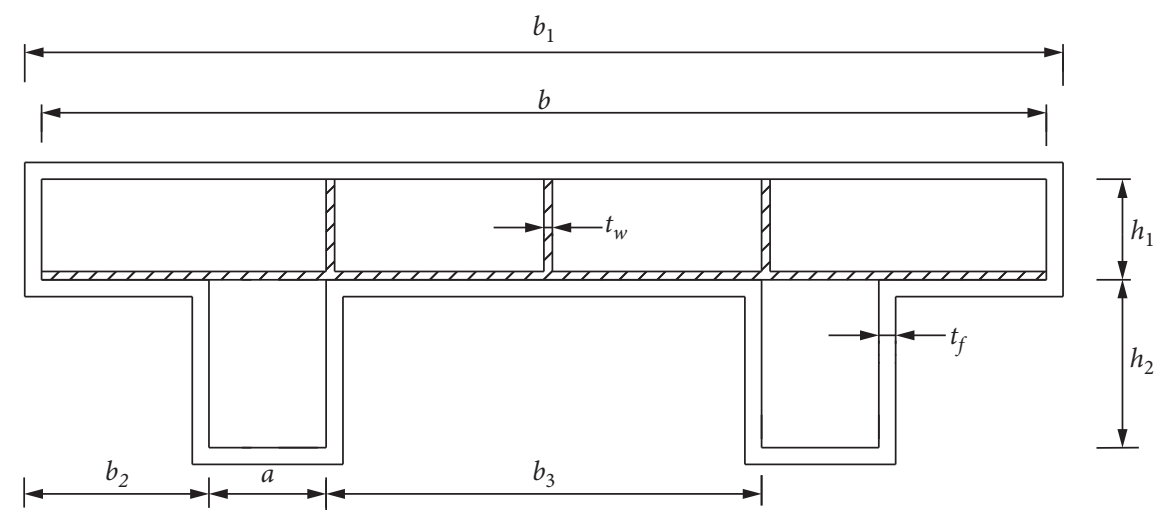

(a)

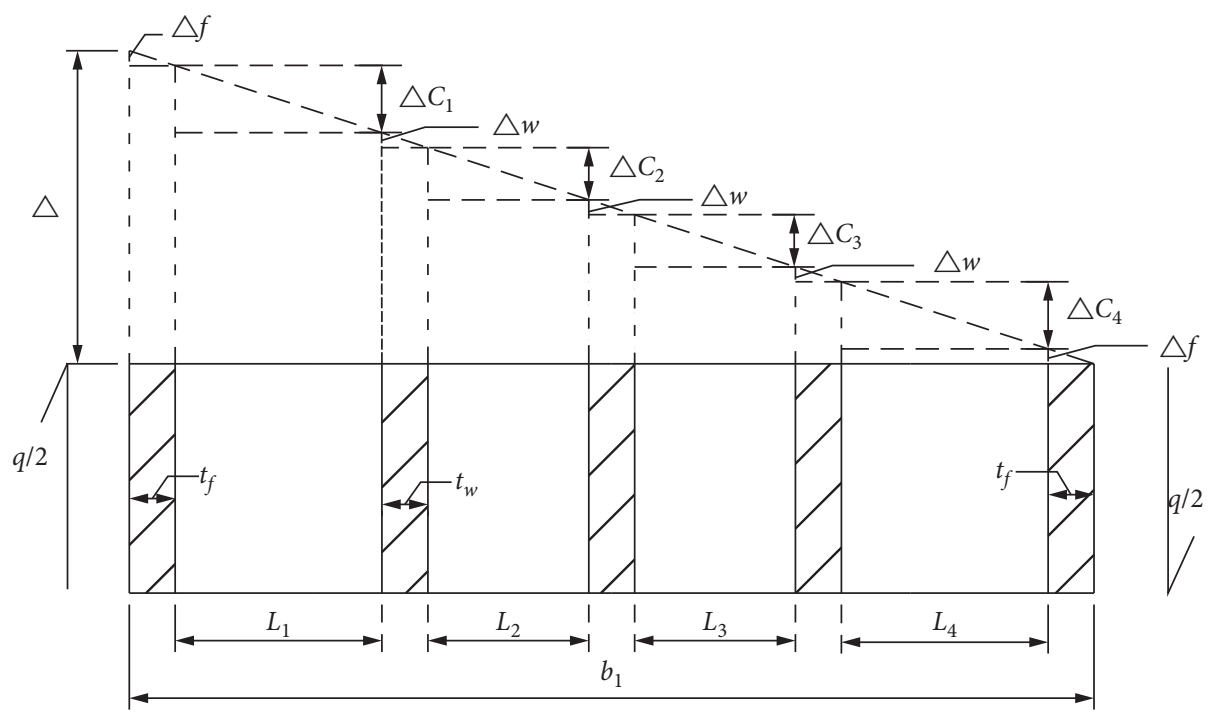

(b)

FIGURE 11: Section of the sandwich deck and the slab configuration under vertical load. (a) Cross section of the deck. (b) Shear deformation of the slab strengthened by webs.

where $\quad d_{1}=h_{1}+h_{2}+1.5 t_{f} \quad-y_{c}, \quad d_{2}=h_{2}+0.5 t_{f} \quad-y_{c} \quad d_{4}=$ $0.5 h_{1}+h_{2}+0.5 t_{f}-y_{c}, d_{5}=0.5 h_{2}+0.5 t_{f}-y_{c}, I_{f}, I_{w v}$ and $I_{w h}$ are the moment of inertia about the neutral axis of the facesheets, vertical and horizontal webs, respectively, $I_{c}$ is the equivalent moment of inertia of the core, and $n$ is the number of vertical webs.

With the transformed section, the equivalent moment of inertia $(I)_{\mathrm{eq}}$ for the integrated decks can be calculated as follows:

$$
I_{\mathrm{eq}}=I_{f}+I_{w v}+I_{w h}+I_{c} \text {. }
$$

6.2. Prediction of Shear Rigidity. Based on the compatibility of shear deformation of foam core and webs under vertical loads, as shown in Figure 11(b), the deformation of core of slab strengthened by webs and facesheets $\Delta$ is given by

$$
\Delta=2 \Delta_{f}+n \Delta_{w}+\sum_{i=1}^{n+1} \Delta_{\mathrm{ci}},
$$

where $\Delta_{f}, \Delta_{w}$, and $\Delta_{\mathrm{ci}}$ are the shear deformations of facesheets, webs, and foam cores under vertical loads, respectively.

From equation (10), the shear strain of cores strengthened by webs and facesheets $\gamma$ is given by

$$
\gamma b_{1}=2 \gamma_{f} t_{f}+n \gamma_{w} t_{w}+\sum_{i=1}^{n+1} \gamma_{c} L_{i}
$$

where $\gamma_{f}, \gamma_{w}$, and $\gamma_{c}$ are the shear strain of facesheets, webs, and cores, respectively, $t_{w}$ is the thickness of the webs, and $L_{i}$ is the width of cores separated by webs.

According to the shear stress constitutive law, the shear stress of cores strengthened by webs and facesheets $\tau$ can be expressed as

$$
\frac{\tau}{G_{0}} b_{1}=\frac{2 \tau_{f} t_{f}}{G_{f}}+\frac{n \tau_{w} t_{w}}{G_{w}}+\frac{\sum_{i=1}^{n+1} \tau_{c} L_{i}}{G_{c}},
$$

where $\tau_{f}, \tau_{w}$, and $\tau_{c}$ are the shear stress of facesheets, webs, and cores, respectively, and $G_{0}, G_{f}, G_{w}$, and $G_{c}$ are the shear 
modulus of core of slab strengthened by webs and facesheets, facesheets, webs, and bare cores, respectively.

It is assumed that no debonding occurred among the cores, facesheets, and webs under vertical loads. Thus, according to the principle of complementary shear stress, the shear stresses of facesheets, webs, and cores have following relationship:

$$
\tau=\tau_{f}=\tau_{w}=\tau_{c} .
$$

Substituting equation (13) into equation (12), we obtain the shear modulus of foam of slab strengthened by webs and facesheets:

$$
\frac{1}{G_{0}}=\frac{2 t_{f}}{G_{f} b_{1}}+\frac{n t_{w}}{G_{w} b_{1}}+\frac{\sum_{i=1}^{n+1} L_{i}}{G_{c} b_{1}}
$$

In the case of foam of ribs, $G_{1}$ is given by

$$
\frac{1}{G_{1}}=\frac{4 t_{f}}{G_{f}\left(2 a+4 t_{f}\right)}+\frac{2 a}{G_{c}\left(2 a+4 t_{f}\right)} .
$$

The equivalent shear rigidity $(G A)_{\mathrm{eq}}$

$$
(G A)_{\mathrm{eq}}=G_{0} A_{0}+G_{1} A_{1} \text {, }
$$

where $A_{0}$ and $A_{1}$ are the areas of slab and ribs.

6.3. Prediction of Deformations. FRP composites display in general a much higher longitudinal-to-shear modulus ratio than isotropic materials and this ratio tends to increase as the anisotropy degree of the material increases. Thus, shear deformation in the composite structures will increase as the anisotropy degree of the material increases [22]. To account for shear deformation, the deformation in the mid-span of composite decks is obtained based on Timoshenko Beam Theory (TBT):

$$
w\left(\frac{L}{2}\right)=\frac{P a\left(3 L^{2}-4 e^{2}\right)}{48 E_{f} I_{\mathrm{eq}}}+\frac{\mathrm{Pe}}{2 k(G A)_{\mathrm{eq}}},
$$

where $P$ is applied load, $L$ is span length, $e$ is the distance from the support to loading point, and $k$ is shear correction factor. $k$ is taken as 1 which is the same as the value in box sections [23].

Because the effects of the cross beams were not considered in analyzing flexural and shear rigidities of the sandwich decks, equation (17) was used to calculate the midspan displacement of the slab-rib integrated sandwich decks without cross beams. Comparisons of the analytical and the measured displacements at the mid-span under the maximum loads showed good agreement, as given in Table 3.

\section{Conclusions}

The flexural behaviors of slab-rib integrated sandwich composite decks were investigated. The results obtained from this study are summarized as follows:

(1) Debonding of the facesheets to the foam core and the local buckling of facesheets on the compressive region governed the failure modes of specimens without webs. The specimens with horizontal webs have similar failure modes to those without webs. The existence of the vertical webs contributes to improving the debonding of the facesheets from the foam core. Moreover, the specimens with lower foam density have smaller debonding area than the specimens with higher foam density, because the lower rigidity of foams allows compatible deformation under debonding loads. The cross beam in the mid-span is not helpful to improve the debonding of facesheets.

(2) Increasing the number of layers of GFRP skins from 2 to 4 and 6 results in $100 \%$ and $214 \%$ increments in load carrying capacities, respectively, while higher density of foam core results in decrease of the ultimate load due to deformation compatibility between GFRP skins and foam core with low density. The existence of horizontal webs has an insignificant effect on both load carrying capacity and rigidity, while the existence of vertical webs contributes to significantly enhancing the load carry capacity of slab-rib sandwich decks. Adding 2 cross beams at the supports is helpful to increase the load carrying capacity to some extent, while adding 3 cross beams at the supports and mid-span is not useful to enhance the load carrying capacity and rigidity.

(3) The analysis program Abaqus Explicit was used to simulate the flexural behaviors of tested specimens. The models provide reasonable simulations of the tested results. The verified model was extended to analyze the influences of the height of vertical webs and GFRP layers on the compressive region.

(4) Based on equivalent method and compatibility of shear deformation, the flexural and shear rigidities were estimated, including the mid-span deflection computations with TBT under 4-point loading. The predicted deflections corresponding to maximum load agree well with the experimental data.

\section{Data Availability}

The test data used to support the findings of this study are available from the corresponding author upon request.

\section{Conflicts of Interest}

The authors declare that they have no conflicts of interest.

\section{Acknowledgments}

The financial support from the National Natural Science Foundation of China (Grant No.51578283), Modern Science and Technology Support Program of Jiangsu Construction Industry of China (Grant No. 2016-13), and Top Six Talent Projects in Jiangsu Province, China (Grant No. JZ-024), is greatly appreciated. Professor Weiqing Liu unfortunately passed away on June 3, 2020. The authors would like to express their gratitude to Professor Liu for his contribution to the paper. 


\section{References}

[1] G. Zi, B. M. Kim, Y. K. Hwang, and Y. H. Lee, "An experimental study on static behavior of a GFRP bridge deck filled with a polyurethane foam," Composite Structures, vol. 82, no. 2, pp. 257-268, 2008.

[2] J. Wang, H. GangaRao, M. Li, M. Liang, and W. Liu, “Axial behavior of columns with glass fiber reinforced polymer composite shells and syntactic foam core," Journal of Composites for Construction, vol. 23, no. 2, Article ID 04018083, 2019.

[3] A. Manalo, S. Surendar, G. van Erp, and B. Benmokrane, "Flexural behavior of an FRP sandwich system with glass-fiber skins and a phenolic core at elevated in-service temperature," Composite Structures, vol. 152, pp. 96-105, 2016.

[4] S. Satasivam and Y. Bai, "Mechanical performance of bolted modular GFRP composite sandwich structures using standard and blind bolts," Composite Structures, vol. 117, pp. 59-70, 2014.

[5] D. Y. Moon, G. Zi, D. H. Lee, B. M. Kim, and Y. K. Hwang, "Fatigue behavior of the foam-filled GFRP bridge deck," Composites Part B: Engineering, vol. 40, no. 2, pp. 141-148, 2009.

[6] T. Sharaf, W. Shawkat, and A. Fam, "Structural performance of sandwich wall panels with different foam core densities in one-way bending," Journal of Composite Materials, vol. 44, no. 19, pp. 2249-2263, 2010.

[7] A. Chen and J. F. Davalos, "Development of facesheet for honeycomb FRP sandwich panels," Journal of Composite Materials, vol. 46, no. 26, pp. 3277-3295, 2012.

[8] H. S. Ji, W. Song, and Z. J. Ma, "Design, test and field application of a GFRP corrugated-core sandwich bridge," Engineering Structures, vol. 32, no. 9, pp. 2814-2824, 2010.

[9] M. Osei-Antw, J. Castro, AP. Vassilopoulos, and T. Keller, "FRP-balsa composite sandwich bridge deck with complex core assembly," Journal of Composites for Construction, vol. 17, no. 6, Article ID 04013011, 2013.

[10] M. Mohamed, S. Anandan, Z. Huo, V. Birman, J. Volz, and K. Chandrashekhara, "Manufacturing and characterization of polyurethane based sandwich composite structures," Composite Structures, vol. 123, pp. 169-179, 2015.

[11] H. Tuwair H, J. Volz, MA. ElGawady, M. Mohamed, K. Chandrashekhara, and V. Birman, "Testing and evaluation of polyurethane-based GFRP sandwich bridge deck panels with polyurethane foam core," Journal of Bridge Engineering, vol. 21, no. 1, Article ID 04015033, 2016.

[12] A. Mostafa, K. Shankar, and E. V. Morozov, "Influence of shear keys orientation on the shear performance of composite sandwich panel with PVC foam core: numerical study," Materials \& Design, vol. 51, pp. 1008-1017, 2013.

[13] E. M. Reis and S. H. Rizkalla, "Material characteristics of 3-D FRP sandwich panels," Construction and Building Materials, vol. 22, no. 6, pp. 1009-1018, 2008.

[14] J. Knippers, E. Pelke, M. Gabler, and D. Berger, "Bridges with glass fibre-reinforced polymer decks: the road bridge in friedberg, Germany," Structural Engineering International, vol. 20, no. 4, pp. 400-404, 2010.

[15] V. Mara, M. Al-Emrani, and R. Haghani, "A novel connection for fibre reinforced polymer bridge decks: conceptual design and experimental investigation," Composite Structures, vol. 117, no. 1, pp. 83-97, 2014.

[16] A. Fettahoglu, "Optimizing rib width to height and rib spacing to deck plate thickness ratios in orthotropic decks," Cogent Engineering:, vol. 3, no. 1, p. 1154703, 2016.
[17] B. Standards, "Design of steel structures-steel bridges: brussel: European committee for standardization: Eurocode 3-design of steel structures-part 2: steel bridges," 2006.

[18] ASTM D638, Standard Test Method for Tensile Properties of Plastics, ASTM International, West Conshohocken, PA, USA, 2014.

[19] ASTM C365/C365-16, Standard test method for flatwise compressive properties of sandwich cores, ASTM International, Conshohocken, PA, USA, 2016.

[20] H. Zhang, C. Zhou, K. Li, P. Gao, Y. Pan, and Z. Zhang, "Material and structural properties of fiber-reinforced resin composites as thin overlay for steel bridge deck pavement," Advances in Materials Science and Engineering, vol. 2019, Article ID 9840502, 13 pages, 2019.

[21] I. Lapczyk and J. A. Hurtado, "Progressive damage modeling in fiber-reinforced materials," Composites Part A: Applied Science and Manufacturing, vol. 38, no. 11, pp. 2333-2341, 2007.

[22] A. B. SS. Neto and H. LL. Rovere, "Flexural stiffness characterization of fiber reinforced plastic (FRP) pultruded beams," Composite Structures, vol. 81, pp. 274-282, 2007.

[23] M. D. Hayes and J. J. Lesko, "Measurement of the timoshenko shear stiffness. I: effect of warping," Journal of Composites for Construction, vol. 11, no. 3, pp. 336-342, 2007. 